\title{
Left ventricular dysfunction, natriuretic peptides, and mortality in an urban population
}

\author{
T A McDonagh, A D Cunningham, C E Morrison, J J V McMurray, I Ford, J J Morton, \\ H J Dargie
}

\begin{abstract}
Objective-To report the mortality of left ventricular systolic dysfunction (LVD), assessed objectively by echocardiography, and its association with natriuretic peptide hormones in a random sample of 1640 men and women aged 25-74 years from a geographical, urban population. Methods-Left ventricular function was measured by echocardiography in 1640 attendees studied in 1992-3. LVD was defined as a left ventricular ejection fraction (LVEF) $\leqslant 30 \%$. Plasma concentrations of N-terminal atrial natriuretic peptide (N-ANP) and brain natriuretic peptide (BNP) were measured by standard radioimmunoassays. Mortality was documented at four years. Results-The four year all cause mortality rate in the whole cohort was $4.9 \%$ (80 deaths). It was $21 \%$ (nine deaths) in those with an LVEF $\leqslant 30 \%$ and $4 \%$ in those whose LVEF was $>30 \%$ $(\mathrm{p}<0.001)$. The median (interquartile range) BNP concentration in those who died was $16.9 \mathrm{pg} / \mathrm{ml}(8.8-27)$ and $7.8 \mathrm{pg} / \mathrm{ml}(3.4-13)$ in survivors $(\mathrm{p}<0.0001)$. Similarly, N-ANP had a median concentration of $2.35 \mathrm{ng} / \mathrm{ml}(1.32-3.36)$ in those with a fatal outcome and $1.27 \mathrm{ng} / \mathrm{ml}$ $(0.9-2.0)$ in those alive at four years $(\mathrm{p}<0.0001)$. Subjects with an LVEF $\leqslant 40 \%$ also had a significant mortality rate of $17 \%$ if they also had a BNP concentration $\geqslant 17.9 \mathrm{pg} / \mathrm{ml}$ compared with $6.8 \%$ if their BNP was below this concentration $(p=0.013)$. Multivariate analysis revealed the independent predictors of four year all cause mortality to be increasing age $(p<0.001)$, a BNP concentration $\geqslant 17.9 \mathrm{pg} / \mathrm{ml}(\mathrm{p}=0.006)$, the presence of ischaemic heart disease $(\mathrm{p}=0.03)$, and male sex $(\mathrm{p}=0.04)$.

Conclusions-LVD is associated with a considerable mortality rate in this population. BNP also independently predicts outcome. In addition to its role as a diagnostic aid in chronic heart failure and LVD, it provides prognostic information and clarifies the meaning of a given degree of LVD. (Heart 2001;86:21-26)
\end{abstract}

Keywords: epidemiology; left ventricular dysfunction; natriuretic peptides

Chronic heart failure (CHF) is usually caused by left ventricular dysfunction (LVD) that, in most cases, is systolic in nature. It is often preceded by a latent phase of asymptomatic LVD. Both symptomatic and asymptomatic LVD are common in the general population. ${ }^{1}$

CHF has long been known to carry a poor prognosis. ${ }^{2}$ There is good evidence from both epidemiological studies and the "heart failure" treatment trials to substantiate that, in its severest categories, its mortality rate exceeds that of many of the common cancers. ${ }^{3-6}$ The mortality conferred by the main precursor of CHF-LVD - has, however, been derived mainly from the heart failure and postmyocardial infarction angiotensin converting enzyme (ACE) inhibitor trials. ${ }^{7-9} \mathrm{~A}$ few population based studies have documented the mortality of $\mathrm{CHF}$ resulting from $\mathrm{LVD}^{10}$ and, to date, none have reported on the mortality of the asymptomatic phase.

Both symptomatic and asymptomatic LVD is associated with increased circulating concentrations of the natriuretic peptide hormones: atrial (ANP) and brain natriuretic peptide (BNP) ${ }^{11}$ The N-terminals of ANP and BNP, in particular, have proved to be good markers of both development of $\mathrm{CHF}$ and prognosis in patient populations with LVD. ${ }^{12-15}$ When ANP and $\mathrm{BNP}$ have been compared in this regard, $\mathrm{BNP}$ has emerged as the stronger predictor of mortality. ${ }^{13-15}$ However, their ability to determine prognosis in the general population is unknown.

This study reports, firstly, the mortality associated with LVD (both symptomatic and asymptomatic) and, secondly, the ability of the natriuretic peptide hormones to determine that prognosis in a random, geographical sample of men and women aged $25-74$ years.

\section{Methods}

POPULATION

The study population consisted of 2000 subjects aged 25-74 randomly sampled from north Glasgow who had attended the third Glasgow MONICA (monitoring trends and determinants in cardiovascular disease) risk factor survey in 1992. This parent population was obtained by a two stage random sampling procedure. Firstly, 30 family practitioners were randomly selected from the 210 in the area. Secondly, patients were randomly selected from each 10 year age/sex band from 25-74 years in proportion to the doctor's list of patients. The population was oversampled to allow for non-response (response rate $67 \%$ ). All responders were invited to attend the present study. Of the 2000 invited, 1653 attended $(83 \%)$.

ECHOCARDIOGRAPHY

We used a left ventricular ejection fraction (LVEF) calculated by the biplane disc summation method (Simpson's rule) as our ideal for 
left ventricular function. This was obtainable in $89.5 \%$ of subjects. LVEF $\leqslant 30 \%$ was defined as significant LVD because it is a $33 \%$ reduction in the mean value of $47.2 \%$ for "normal" subjects within this population. The echocardiographic methods are described in more detail elsewhere. ${ }^{1}$

\section{ELECTROCARDIOGRAPHY}

Standard 12 lead ECGs were coded using the Minnesota coding criteria. ${ }^{16}$ ECGs were classified as "ischaemic" if they contained a pathological $\mathrm{Q}$ wave or an ST/T segment abnormality. The ECGs were all coded by two readers and discrepancies in coding were adjudicated by a third coder.

VENOUS BLOOD SAMPLES

Venous blood was withdrawn after 20 minutes of supine rest into chilled tubes containing EDTA and trasylol $(50 \mathrm{U} / \mathrm{ml})$. Both $\mathrm{N}$ terminal ANP (N-ANP) and BNP concentrations were measured after extraction from plasma by standard radioimmunoassays (Peninsula, California, USA) and have been previously described in detail. ${ }^{11}{ }^{1718}$ Natriuretic peptide concentrations were analysed in 1252 subjects.

QUESTIONNAIRE AND OTHER MEASUREMENTS

A self reported questionnaire was obtained for all subjects giving details of a prior history of myocardial infarction, angina, hypertension, or diabetes. Drug treatment was also recorded. Blood pressure was measured with a random zero sphygmomanometer (mean of two readings). Hypertension was defined as a history of hypertension, a measured blood pressure of $>140 \mathrm{~mm} \mathrm{Hg}$ systolic or $>90 \mathrm{~mm} \mathrm{Hg}$ diastolic, or current treatment with an antihypertensive agent.

Diabetes was defined as either a history of diabetes or the current prescription of either an oral hypoglycaemic agent or insulin.

The presence of a myocardial infarction was diagnosed either if a subject gave a history of prior myocardial infarction or by the presence of a pathological $\mathrm{Q}$ wave on the ECG. Angina was determined by a history of physician diagnosed angina or the current use of nitrate drugs. The category "ischaemic heart disease" was defined as either the presence of angina, or a history or ECG evidence of ischaemia or myocardial infarction.

MORTALITY AND CLASSIFICATION OF CAUSE OF DEATH

The main mortality reported is all cause at four years of follow up.

Cause of death was classified by three independent observers (TMCD, HJD, and ADC) scrutinising the death certificate reports. Discrepancies were resolved by discussion. The categories assigned were as follows:

- Coronary heart disease - including death from myocardial infarction, angina, and ischaemic heart disease occurring in position one.
- Cardiovascular - the above causes and deaths resulting from cerebrovascular disease, mesenteric emboli, and peripheral vascular disease (mainly ruptured abdominal aortic aneursym).

- Cancer-deaths with a malignant tumour in position one.

- Other-deaths not accounted for in any of the above categories-for example, suicide, drowning, perforated duodenal ulcer, etc.

STATISTICAL ANALYSIS

The concentrations of the natriuretic peptides are expressed as medians with the interquartile ranges in parentheses. The concentrations of the natriuretic peptides in survivors and non-survivors were tested using the MannWhitney $U$ test. A univariate Cox regression survival analysis was used to determine univariate predictors of all cause mortality. A stepwise (forward) multiple Cox regression survival analysis was carried out to determine the independent predictors of that mortality. Variables included in the model were those that achieved significance as univariate variables. Entry into the model was at the $5 \%$ level and removal at the $10 \%$ cut off point. In the multiple regression analysis age was treated as a continuous variable (hazard ratios were determined for five year increments); all other covariates were categorical. Of the categorical variables all were dichotomous with the exception of "smoking", which was divided into current, former, and never. The cut off points for LVD and the concentrations of BNP and $\mathrm{N}-\mathrm{ANP}$ were $30 \%, 17.9 \mathrm{pg} / \mathrm{ml}$, and $1.76 \mathrm{ng} /$ $\mathrm{ml}$, respectively. ${ }^{11}$ Kaplan-Meier survival curves were constructed for a BNP cut off point of $17.9 \mathrm{pg} / \mathrm{ml}$, LVEF categories of $\leqslant 30 \%$, $\leqslant 35 \%$, and $\leqslant 40 \%$, and an LVEF $\leqslant 40 \%$ stratified according to the BNP cut off point. Differences between the resulting survival curves were assessed by the log rank test. Significance was taken as a $\mathrm{p}<0.05$.

ETHICS

Ethical approval was obtained from both the hospital and the local general practitioner ethical committees.

\section{Results}

Table 1 shows the characteristics of the study population in whom an echocardiogram was obtainable; 1640 attended for screening, 1467 $(89.5 \%)$ had an analysable echocardiogram, and $1252(76 \%)$ subjects had both a venous blood sample and an analysable echocardiogram available.

The cohort was screened in 1992-3. This analysis refers to four years of follow up.

The four year all cause mortality rate in the cohort was $4.9 \%$ (80 deaths). Thirty seven $(47 \%)$ of these were cardiovascular in nature, $24(30 \%)$ resulted from coronary heart disease, 30 were attributable to cancer (38\%), and 12 $(15 \%)$ were classified as "other". Because of the relatively small number of deaths for each cause, all subsequent analysis refers to all cause mortality. 
Table 1 Characteristics of the study population (age range 25-74 years)

\begin{tabular}{ll}
\hline Age (years) & $50.4(14)$ \\
Male sex & $48.2 \%(707)$ \\
Evidence of IHD & $23 \%(324)$ \\
Breathlessness & $9.8 \%(144)$ \\
Hypertension & $23.8 \%(344)$ \\
Diabetes & $2.5 \%(37)$ \\
Left ventricular dysfunction & $2.9 \%(43)$ \\
$\quad$ Asymptomatic & $49 \%(20)$ \\
Symptomatic & $51 \%(21)$ \\
Ischaemic cause & $83 \%(35)$ \\
\hline
\end{tabular}

Values are mean (SD) or percentage (number) of group. Ischaemic heart disease (IHD) refers to a history of angina or treatment with nitrates, a history of myocardial infarction or ECG evidence of $\mathrm{Q}$ waves, or a significant ST-T segment abnormality. Breathlessness refers to cardiac dyspnoea according to the Medical Research Council breathlessness questions (in the absence of cough and/or sputum production for more than three days of the week for three months of the year). Hypertension is a measured blood pressure of $>140 \mathrm{~mm} \mathrm{Hg}$ systolic and/or $90 \mathrm{~mm} \mathrm{Hg}$ diastolic and/or current treatment with an antihypertension drug. Diabetes is defined as a history of physician diagnosed diabetes and/or treatment with an oral hypoglycaemic agent and/or insulin. Left ventricular dysfunction is a left ventricular ejection fraction $\leqslant 30 \%$.

Table 2 Mortality according to left ventricular ejection fraction (LVEF)

\begin{tabular}{ll}
\hline LVEF & All cause mortality \\
\hline$>40 \%$ & $3.4 \%(40 / 1194)$ \\
$>35 \%$ & $3.8 \%(52 / 1354)$ \\
$>30 \%$ & $4.1 \%(58 / 1424)$ \\
$\leqslant 30 \%$ & $21 \%(9 / 43)$ \\
$\leqslant 35 \%$ & $13.3 \%(15 / 113)$ \\
$\leqslant 40 \%$ & $9.8 \%(17 / 273)$ \\
\hline
\end{tabular}

Table 2 lists the four year mortality rates according to subjects' baseline LVEF category. In those with significant LVD, the all cause four year mortality rate was $21 \%$ (nine) compared with $4 \%$ (58) in those whose LVEF was greater than $30 \%(\mathrm{p}<0.0001)$. The all cause mortality was $20 \%$ (four) in subjects with symptomatic LVD and $25 \%$ (five) in asymptomatic LVD (NS). Similarly, there was no significant difference between symptomatic and asymptomatic patients in the mortality of any degree of LVD, whether LVEF was $\leqslant 40 \%$ or $\leqslant 35 \%$.

The median (interquartile range) BNP concentration in those who died, irrespective of the cause, was $16.9 \mathrm{pg} / \mathrm{ml}$ (8.8-27) compared with $7.8 \mathrm{pg} / \mathrm{ml}(3.4-13)$ in survivors $(\mathrm{p}<0.0001)$. Similarly, patients who died had a median concentration of N-ANP of $2.35 \mathrm{ng} / \mathrm{ml}(1.32$ 3.36) compared with $1.27 \mathrm{ng} / \mathrm{ml}(0.9-2.0)$ in those alive at four years $(\mathrm{p}<0.0001)$.

Table 3 lists the results of the univariate Cox regression analysis for all cause mortality. The significant univariate predictors were age, male

Table 3 Univariate predictors of all cause mortality

\begin{tabular}{llc}
\hline Factor & Hazard ratio $(95 \%$ CI) & p Value \\
\hline Increasing age (per 5 years) & $1.6(1.4$ to 1.8$)$ & $<0.0001$ \\
Sex (male $v$ female) & $1.8(1.1$ to 3.0$)$ & 0.02 \\
Former smoker $v$ non-smoker & $0.3(0.2$ to 0.8$)$ & 0.009 \\
Current smoker $v$ non-smoker & $1.0(0.6$ to 1.7$)$ & 0.99 \\
LVEF $\leqslant 30 \%$ & $6.0(2.9$ to 12.0$)$ & $<0.0001$ \\
Diabetes & $3.4(1.4$ to 8.4$)$ & 0.009 \\
IHD & $4.2(2.5$ to 6.8$)$ & $<0.001$ \\
Hypertension & $3.8(2.3$ to 6.1$)$ & $<0.001$ \\
BNP $\geqslant 17.9 \mathrm{pg} / \mathrm{ml}$ & $5.1(3.1$ to 18.4$)$ & $<0.0001$ \\
N-ANP $\geqslant 1.76 \mathrm{ng} / \mathrm{ml}$ & $3.4(2.0$ to 5.7$)$ & $<0.0001$
\end{tabular}

Age was treated as a continuous variable; all other factors were categorical. With the exception of smoking all other covariates were dichotomous; smoking was divided into current, former or never. Hazard ratios were calculated for the presence of the risk factor shown compared with its absence. $\mathrm{BNP}$, brain natriuretic peptide; N-ANP, N-terminal atrial natriuretic peptide. sex, the presence of ischaemic heart disease, hypertension, significant LVD or diabetes, being a former smoker, or having a BNP concentration $\geqslant 17.9 \mathrm{pg} / \mathrm{ml}$ or an N-ANP concentration $\geqslant 1.76 \mathrm{ng} / \mathrm{ml}$. Entering these variables into a stepwise Cox regression model resulted in four variables being included in the model: advancing age (per five year increment $\mathrm{p}<0.0001$, hazard ratio 1.5 (95\% confidence interval (CI) 1.3 to 1.6$)$ ), a BNP concentration $\geqslant 17.9 \mathrm{pg} / \mathrm{ml} \quad(\mathrm{p}=0.006$, hazard ratio 2.2 (95\% CI 1.2 to 3.8$)$, the presence of ischaemic heart disease $(p=0.03$, hazard ratio 1.9 (95\% CI 1.1 to 3.2 ), and male sex $(\mathrm{p}=0.04$, hazard ratio $1.8(95 \%$ CI 1.0 to 3.1). When N-ANP was substituted for BNP in the model, N-ANP did not achieve significance. Similarly, when N-ANP or LVD (LVEF $\leqslant 30 \%$ ) was forced into the model, BNP was still significant.

Figure 1 depicts the Kaplan-Meier curves stratified by LVEF categories. It can be seen that survival was poorest in those with an LVEF $\leqslant 30 \%$ (21\% four year mortality), was intermediate at $13.3 \%$ in those with an LVEF $\leqslant 35 \%$, and was still significantly increased at $9.8 \%$ in those with $\mathrm{LVEF} \leqslant 40 \%$ $(\mathrm{p}<0.001)$.

Mortality also increased as the concentration of BNP increased. These data are shown for four cut off points of BNP in fig 2 .

Figure 3 shows Kaplan-Meier survival curves constructed for all cause mortality stratified according to the optimum diagnostic concentration BNP of $\geqslant 17.9$ or $<17.9 \mathrm{pg} / \mathrm{ml}$ $(p<0.001)$. Repeating the analysis for those with an LVEF $\leqslant 40 \%$ stratified according to the presence or absence of an increased BNP concentration $(\geqslant 17.9 \mathrm{pg} / \mathrm{ml})$ showed that those with a high BNP had a four year all cause mortality rate of $17 \%$ compared with $6.8 \%$ in those with a BNP concentration $<17.9 \mathrm{pg} / \mathrm{ml}$ $(p=0.013)$ (fig 4).

Patients with preserved systolic function (LVEF $>40 \%$ ) also had a significantly higher mortality if the BNP concentration was $\geqslant 17.9 \mathrm{pg} / \mathrm{ml}$ at $8.5 \%(\mathrm{n}=16$ of 118$)$ compared with $2 \%(n=21$ of 891$)$ in those with a BNP concentration $<17.9 \mathrm{pg} / \mathrm{ml}(\mathrm{p}<0.0001)$.

\section{Discussion}

This is the first reported study of the mortality associated with LVD in an unselected population derived from the community as opposed to that of patients recruited for clinical trials. We have shown that significant LVD is associated with a substantial mortality rate of $21 \%$, five times that of the general population with LVEF $>30 \%$ and six times that of patients with LVEF $>40 \%$. Our study included subjects with both symptomatic and asymptomatic LVD, and is not directly comparable with other epidemiological studies of the mortality of $\mathrm{CHF}$, the symptomatic end of the spectrum. At the same time, LVD in our study conferred an increment in mortality similar to that of the population in the Framingham heart study's 40 year follow-up, in which the CHF mortality rate was six times that of the age corrected normal population. ${ }^{3}$ The absolute five year all 


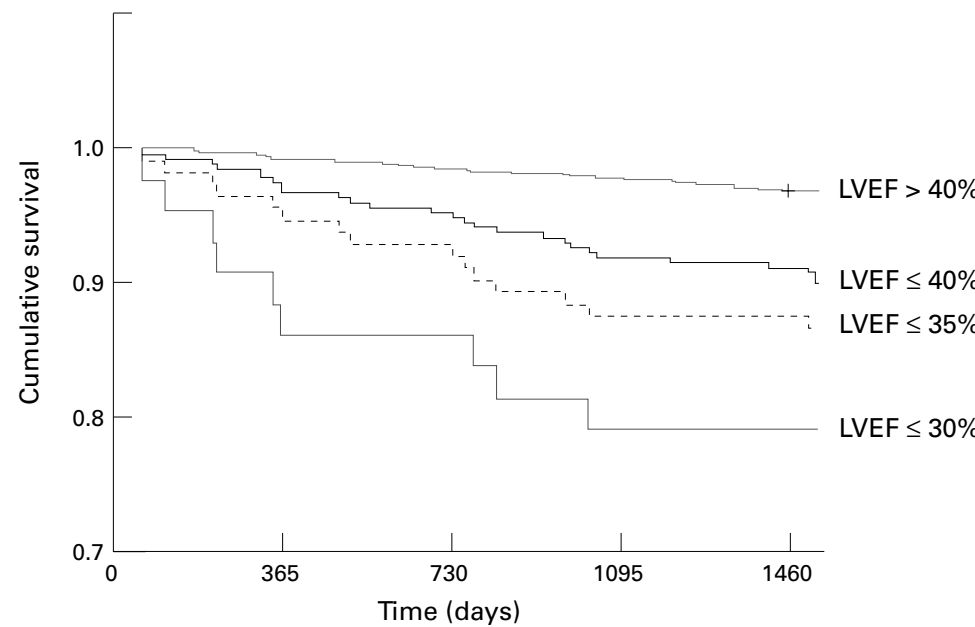

Figure 1 Kaplan-Meier survival curves for left ventricular ejection fraction (LVEF) categories $(>40 \%, \leqslant 40 \%, \leqslant 35 \%$, and $\leqslant 30 \%)$. The $p$ values above and below the respective LVEF cut off points were as follows: $L V E F \leqslant$ and $>40 \%, p<0.0001 ; L V E F \leqslant$ and $>35 \%, p<0.0001 ; L V E F \leqslant$ and $>30 \%, p<0.001$. The number of subjects in each ejection fraction category was as follows: $L V E F>40 \%=1194 ; \mathrm{LVEF} \leqslant 40 \%=273$; $L V E F \leqslant 35 \%=113 ; L V E F \leqslant 30 \%=43$.

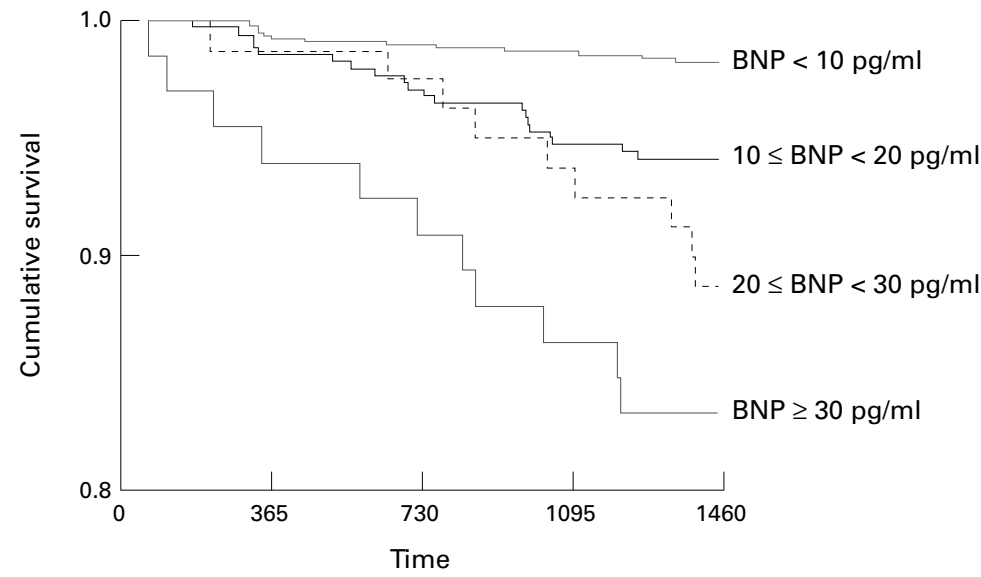

Figure 2 Kaplan-Meier survival curves for various categories of brain natriuretic peptide (BNP) concentrations $(<10 \mathrm{pg} / \mathrm{ml}, 10 \leqslant B N P<20 \mathrm{pg} / \mathrm{ml}, 20 \leqslant B N P<30 \mathrm{pg} / \mathrm{ml}$, and $B N P \geqslant 30 \mathrm{pg} / \mathrm{ml})$. The actual mortality rates $\%(\mathrm{n})$ for these categories were $2 \%(16)$, $6.7 \%$ (23), $12.5 \%$ (10), and $18 \%$ (12), respectively. The log rank statistic was 53, $p<0.0001$.

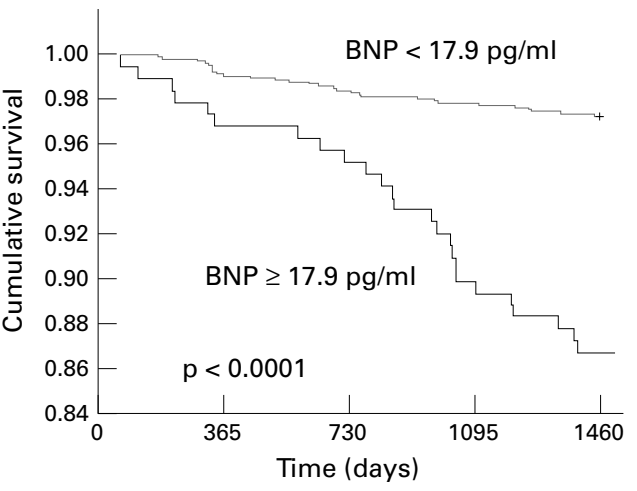

Figure 3 Kaplan-Meier survival curves for BNP dichotomised at a concentration of $17.9 \mathrm{pg} / \mathrm{ml}$. There were 33 deaths 1067 (3.1\%) in those with BNP $<17.9 \mathrm{pg} / \mathrm{ml}$ and 28 deaths 188 at risk $(14.9 \%)$ in those with an increased BNP concentration ( $p<0.0001$, log rank statistic 49.5).

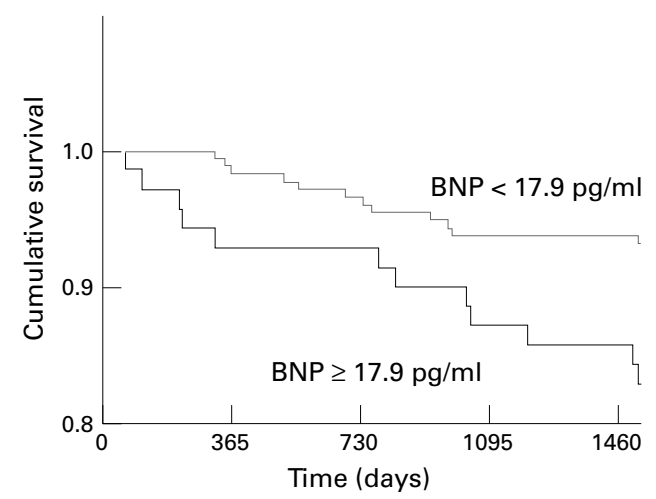

Figure 4 Kaplan-Meier survival curves for those with a left ventricular ejection fraction categories of $\leqslant 40 \%$ stratified by a BNP concentration < 17.9 or $\geqslant 17.9 \mathrm{pg} / \mathrm{ml}$. The $p$ value was 0.013 . There were 12 deaths $175(6.8 \%)$ in those with a $B N P<17.9 \mathrm{pg} / \mathrm{ml}$ and 12 deaths $/ 70$ at risk $(17 \%)$ in those with an increased BNP concentration.

prevention study at $15.8 \%{ }^{8}$ and the treatment study at $39 \%$.

Our results are unlikely to be significantly confounded by the effects of drugs because only $19 \%$ of our patients with symptomatic LVD were being treated with an ACE inhibitor and the time scale of our study predates the routine use of $\beta$ adrenoceptor blockade for heart failure.

Our study has also shown, for the first time in the general population aged $25-74$ years, that $\mathrm{BNP}$ is an independent predictor of all cause mortality. In terms of population based work the only other study of the power of BNP in determining subsequent all cause prognosis is that of Wallen and colleagues, ${ }^{21}$ who similarly found BNP to be the best predictor of death in 541 elderly patients over the age of 85 years. Other work in an elderly population has also shown that ANP is associated with an adverse prognosis. ${ }^{22}$ This work reinforces the earlier studies in patient populations, which have vindicated the utility of BNP in determining mortality after myocardial infarction and in $\mathrm{CHF} .{ }^{12-15}$

Our results also confirm previous reports comparing N-ANP with $\mathrm{BNP}$ in predicting mortality, showing that $\mathrm{BNP}$ is superior in this regard. ${ }^{13-15}$

In an earlier study documenting the prevalence of LVD in this population, ${ }^{1}$ we tackled 
the question, "What is abnormal left ventricular function?" given that LVEF is normally distributed. In an individual patient, statistically normal or abnormal values may have little meaning; the change from their premorbid ejection fraction is more likely to be important. This work allows us to ascertain more clearly what constitutes LVD in that a meaningful test of left ventricular function should give some indication of prognosis. Our original assumption that an LVEF $\leqslant 30 \%$ is biologically abnormal has been confirmed in that this group of patients had the poorest survival. However, subjects with $\mathrm{LVEF} \leqslant 35 \%$ and $\leqslant 40 \%$ also have a higher mortality rate. The cut off point of $40 \%$ is also well within the statistical boundaries of normality for our measurement of LVEF in this population. Our results point to a role for $\mathrm{BNP}$ in clarifying whether a given LVEF is indeed biologically abnormal, in that subjects with an LVEF $\leqslant 40 \%$ who had a raised BNP concentration had a four year mortality rate of $17 \%$ (much closer to the LVEF $\leqslant 30 \%$ level of $21 \%$ ) compared with only $6.8 \%$ in those with $\mathrm{LVEF} \leqslant 40 \%$ with a low BNP concentration.

These findings raise some speculation as to why BNP is associated with mortality. The possibilities for this include that it is merely reflecting cardiac or left ventricular dysfunction more accurately than current cardiological measurements of these parameters.

Several cardiological reasons may account for the association of an abnormally high BNP concentration and an LVEF that can be variously described as "borderline" or even "preserved". Firstly, a patient may originally have had a much higher LVEF that, as a result of intervening cardiac pathology, is now lower but still within the statistically normal range. Alternatively, an abnormality of ventricular function other than systolic dysfunction, such as abnormal relaxation or "diastolic dysfunction" 23 - for example, caused by left ventricular hypertrophy - may be responsible for the elevation in BNP concentration. ${ }^{24}$ Interestingly, in this study patients with preserved systolic function who had a high BNP concentration also had a worse prognosis. Non-cardiological causes of a raised BNP such as renal impairment also have to be borne in mind. ${ }^{23}$ Alternatively, it may be reflecting pre-morbid multisystem dysfunction with not only deteriorating cardiac function but also renal impairment, which is known to increase circulating concentrations of natriuretic peptide hormones. ${ }^{25}$ Lastly, it is also possible that BNP may have a deleterious pathophysiological role in causing a decline in left ventricular function. There is some preliminary evidence to support this, in that ANP has been shown to cause apoptosis in rat myocytes. ${ }^{26}$

Any detailed discussion or indeed statistical analysis relating left ventricular function or natriuretic peptides to the causes of death in our study has to be avoided because we are limited by the relatively small number of deaths at this point in follow up and this will be the subject of further study.
In our previous published work, we have shown that LVD is common, that much of it is asymptomatic, that it is undertreated, and that it is detectable by BNP analysis. ${ }^{11}$ This study has added to the overall picture of LVD in the population by confirming that it is associated with a substantial mortality rate. This reinforces the need to diagnose LVD, be it asymptomatic or symptomatic, earlier and more accurately, to improve eventually its poor outlook. The case for BNP having a role in facilitating that diagnosis, in interpreting the importance of the degree of left ventricular dysfunction, and in estimating prognosis is becoming difficult to ignore.

This study was funded by a grant from the Scottish Office Home and Health Department. The natriuretic peptide assays were funded by Merck Sharpe and Dohme. The echocardiograms were performed by Mrs E Rooney.

1 McDonagh TA, Morrison CE, Lawrence A, et al. Symptomatic and asymptomatic left-ventricular systolic dysfunction in an urban population. Lancet 1997:350:829-33.

2 McKee PA, Castelli WP, McNamara PM, et al. The natural history of congestive heart failure: the Framingham study. N Engl f Med 1971;285:1441-6.

3 Ho KK, Anderson KM, Kannel WB, et al. Survival after the onset of congestive heart failure in Framingham heart study subjects. Circulation 1993;88:107-15.

4 Pitt B, Cohn JN, Francis GS, et al. The effect of treatment on survival in congestive heart failure. Clin.Cardiol 1992;15:323-9.

5 Schocken DD, Arrieta MI, Leaverton PE, et al. Prevalence and mortality rate of congestive heart failure in the United States. 7 Am Coll Cardiol 1992;20:301-6.

6 Rodeheffer RJ, Jacobsen SJ, Gersh BJ, et al. The incidence and prevalence of congestive heart failure in Rochester, and prevalence of congestive heart failure in

7 The SOLVD Investigators. Effect of enalapril on survival in patients with reduced left ventricular ejection fractions and patients with reduced left ventricular ejection fractions and

congestive heart failure. $N$ Engl 7 Med 1991;325:293-302.
The SOLVD Investigators. Effect of enalapril on mortality and the development of heart failure in asymptomatic patients with reduced left ventricular ejection fractions. $N$ Engl f Med 1992;327:685-91.

9 Pfeffer MA, Braunwald E, Moye LA, et al. Effect of captopril on mortality and morbidity in patients with left ventricular dysfunction after myocardial infarction. Results of the survival and ventricular enlargement trial. The SAVE investigators. N Engl f Med 1992;327:669-77.

10 Senni M, Tribouilloy CM, Rodeheffer RJ, et al. Congestive heart failure in the community. Circulation 1998;98:2282-9.

11 McDonagh TA, Robb SD, Murdoch DR, et al. Biochemical detection of left ventricular systolic dysfunction. Lancet 1998;351:9-13.

12 Hall C, Rouleau JL, Moye MD, et al. N-Terminal proatrial natriuretic factor:an independent predictor of long term prognosis after myocardial infarction. Circulation 1994;89: 1934-42

13 Omland T, Aakvaag A, Bonarjee VVS, et al. Plasma brain natriuretic peptide as an indicator of left ventricular systolic function and long-term survival after acute myocardial infarction: Comparison with plasma atrial natriuretic peptide and N-terminal proatrial natriuretic peptide. Circulation 1996;93:1963-9.

14 Pacher R, Stanek B, Hulsmann M, et al. Prognostic impact of big endothelin-1 plasma concentrations compared with nvasive hemodynamic evaluation in severe heart failure. 7 Am Coll Cardiol 1996;27:633-41.

15 Richards AM, Nicholls G, Yandle TG, et al. Plasma N-terminal pro-brain natriuretic peptide and adrenomedullin: new neurohormonal predcitors of left ventricular function and prognosis after myocardial infarcventricular function and prognosis
tion. Circulation 1998;97:1921-9.

16 Prineas RJ, Crow RS, Blackburn H. The Minnesota code manual of electrocardiographic findings: standards and procedures for measurement and classification. Littleton: John Wright/PSG, 1982.

17 Heublein DM, Heser DW, Edwards BS, et al. N-terminal (1-25) atrial natriuretic factor in human congestive heart failure: a marker for endogenous secretion. $f \mathrm{Am}$ Coll Cardiol 1989;13:9A

18 Lang CC, Choy AMJ, Turner K, et al. The effect of intravenous saline loading on plasma levels of brain natriuretic peptide in man. F Hypertens 1993;11:737-41.

19 Eriksson H, Svardsudd K, Larsson B, et al. Risk factors for heart failure in the general population. The study of the men born in 1913. Eur Heart f 1989;10:647-56.

20 Pousse F, Insard R, Lechat P, et al. Prognostic value of plasma endothelin-1 in patients with chronic heart failure. Eur Heart f 1997;18:254-8.

21 Wallen $\mathrm{T}$, Landahl S, Hedner $\mathrm{T}$, et al. Brain natriuretic peptide predicts mortality in the elderly. Heart 1997;77: 264-7. 
22 Iivanainen AM, Tikkanen I, Tilvis $\mathrm{R}$, et al. Associations between atrial natriuretic peptides, echocardiographic findings and mortality in an elderly population sample. $\mathcal{F}$ Intern Med 1997;241:261-8.

23 Clarkson PBM, Whelldon NM, MacFadyen RJ, et al. Effects of brain natriuretic peptide on exercise hemodynamics and neurohormones in isolated diastolic heart failure. Circulation 1996;93:2037-42.
24 Kohno $\mathrm{M}$, Horio $\mathrm{T}$, Yokokawa $\mathrm{K}$, et al. Brain natriuretic peptide as a cardiac hormone in essential hypertension. Am 1992;92:29-34.

25 Wei CM, Heublein DM, Perrella MA, et al. Natriuretic peptide system in human heart failure. Circulation 1993;88: $1004-9$

26 Wu CF, Bishopric NH, Pratt RE. Atrial natriuretic peptide induces apoptosis in neonatal rat cardiac myocytes. $\mathcal{F}$ Biol Chem 1997;272:14860-6.

\section{IMAGES IN CARDIOLOGY}

\section{Structural failure of a coronary stent}

A 71 year old man was admitted for treatment of a symptomatic severe stenosis of the right coronary artery. After balloon angioplasty, two $16 \mathrm{~mm}$ long stents were placed with a $2.5 \mathrm{~mm}$ balloon (inflation pressure $20 \mathrm{~atm}$ ) to cover a dissection at the dilated vessel segment. The implanted stents were multicellular steel stents with an iridium oxide coating to enhance visibility and biocompatibility (Lunar IrOxStent, InFlow Dynamics, Munich, Germany). The final angiographic result is illustrated (below left, image A). The adjacent image B shows the stented segment without contrast injection where the stents are highly visible. It illustrates that they are all well expanded, and there is minimal overlap of the two stents.

Four months after the procedure, the patient developed recurrent symptoms and was referred to us again. In the follow up angiogram there was a subtotal occlusion in the mid section of the stented segment (below right, image $\mathrm{A}$ ). The adjacent image $\mathrm{B}$ shows the stented segment without contrast injection. It reveals a compressed segment of the distal stent. Compared to the initial result, the outer diameter in this segment of the stent was compressed from $2.7 \mathrm{~mm}$ to $1.8 \mathrm{~mm}$. The outer diameters of other segments were unchanged. Repeat angioplasty was not successful as the compressed stent segment could not be passed with a guide wire.

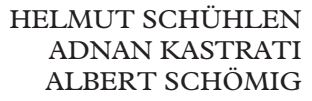

\section{ALBERT SCHÖMIG}

h.schuehlen@med1.med.tu-muenchen.de
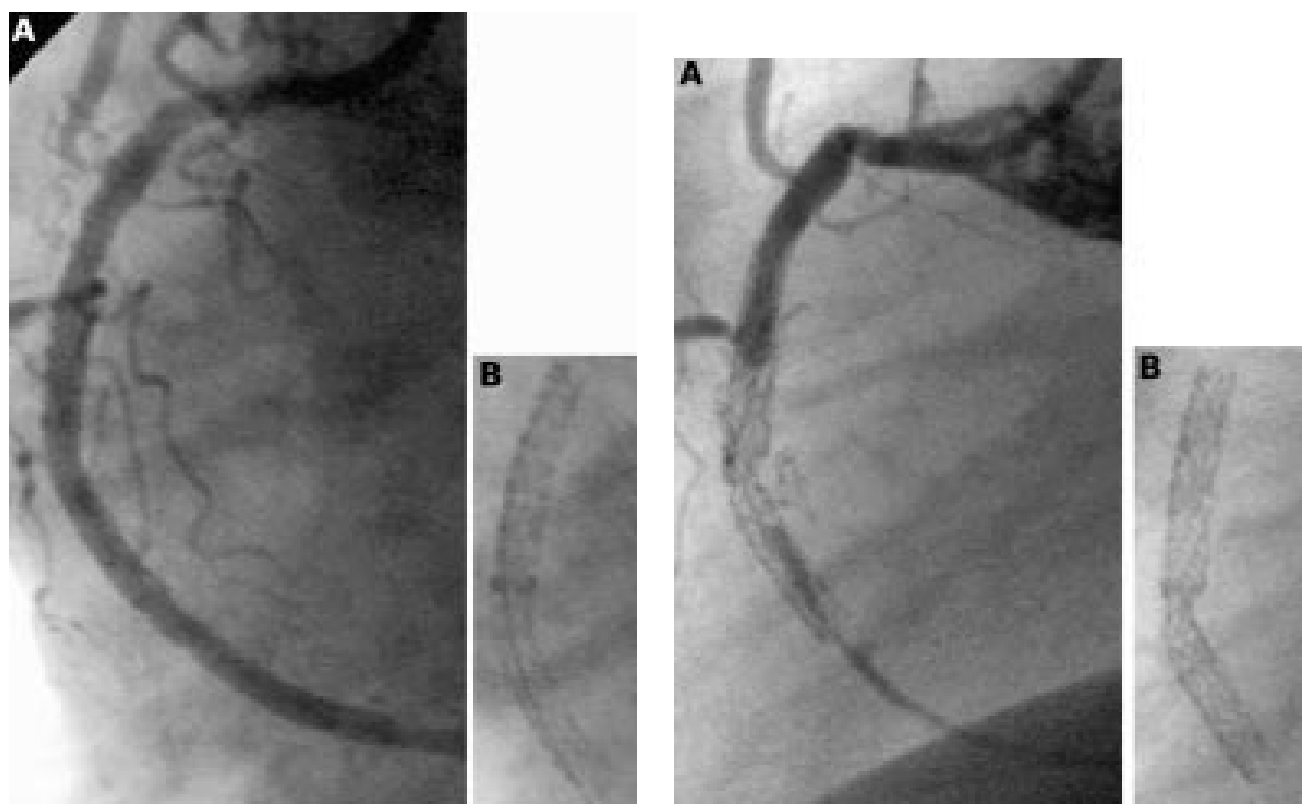